\title{
Value of Increased Serum Lactate in Critically Ill Children in Pediatric Intensive Care Unit and Its Association with Worse Outcome \\ Mohamed Mahmoud Romih ${ }^{1}$, Dina Tawfeek Sarhan', Ahmed Mohamed Baraka², Mohamed Abdelhalem Mohamed ${ }^{* 1}$ \\ Departments of ${ }^{1}$ Pediatrics and ${ }^{2}$ Clinical pathology - Faculty of Medicine, Zagazig University \\ *Corresponding author: Mohamed Abdelhalem Mohamed; Email: besideyoubimo@yahoo.com, Mobile: (+20) 01018129676
}

\begin{abstract}
Background: There is increasing evidence that lactate and hyperlactatemia can be a marker for the outcome in critically ill children. Objective: Our study aimed to describe the prognostic value of increased serum lactate in critically ill children and its association with worse outcome.

Patients and methods: This prospective observational (cohort) study was carried out in Pediatric Intensive Care Unit (PICU) and Clinical Pathology Department at Zagazig University Hospitals over a period of 6 months started from august 2018 till January 2019, it included 86 critically ill children. The study was approved by Ethics Committee, Faculty of Medicine, Zagazig University.

Results: Serum lactate was significantly higher among died cases than survived. Conclsuion: Hyperlactatemia in critically ill children is associated with worse outcome in critically ill patient in PICU.
\end{abstract}

Keywords: Hyperlactatemia, outcome, children, PICU.

\section{INTRODUCTION}

Critically ill children due to various underlying disease processes often have diminished tissue perfusion. Delay in recognition of hypoperfusion leads to development of multi-organ dysfunction syndrome (MODS). This result in morbidity and increased mortality until it is timely recognized and promptly reversed ${ }^{(\mathbf{1})}$.

These patients need intensive monitoring of organs functions such as functions related to the cardiovascular, the respiratory, and the neurological systems. Most critically ill patients are transferred to the intensive care unit (ICU) for close monitoring ${ }^{(2)}$.

Albumin (3), lactic acid (4), procalcitonin (5), glucose ${ }^{(6)}, \mathrm{PaO}_{2}{ }^{(7)}$ and nutritional status ${ }^{\left({ }^{(8)}\right.}$ have been reported as indicators of the risk of mortality in patients who are severely ill.

Lactic acid (LA), a by-product of anaerobic metabolism has been used as a biomarker and indicator of tissue hypoxia. This tissue hypoxia may result from respiratory or circulatory disorders ${ }^{(9)}$.

There is increasing evidence available that clinical signs lag biomarkers like lactate and tissue hypoperfusion do not always show clinical signs, hyperlactatemia can be the only marker for this disorder ${ }^{(1,9)}$.

We report the incidence of hyperlactatemia and its relationship with outcome in critically ill children admitted in PICU.

\section{SUBJECTS AND METHODS}

This study was carried out in Pediatric Intensive Care Unit (PICU) and Clinical Pathology Department at Zagazig University Hospitals over a period of 6 months started from August 2018 till January 2019, it included 86 critically ill children.

\section{Ethical approval}

This study was approved by the Institutional Review Board (IRB) and was done after ethical approval of the Ethical Committee of Research Centre in Zagazig University Hospital and informed written parental consent from every subject that participated in this work.

Inclusion Criteria: Patients admitted to PICU for more than 24 hours and aged from 1 month to 16 years including both males and females.

Exclusion Criteria: Patients whose parents refused participation in the study. Neonates aged $<28$ days and patients who stayed in the PICU for $<24$ hours.

All the participating patient were subjected to the following:

I-Full detailed history including:

a- Personal history included age, sex.

b- History of present illness.

c- Past history of previous hospitalization, PICU admission, medications, blood or blood products transfusion.

d- History of immunization.

e- Developmental and nutritional history.

f- Family history.

\section{II-Full clinical examination: \\ 1-General examination \\ 2-Chest examination. \\ 3- Significant congenital anomalies. \\ 4- Neurological examination: including reflexes, muscle tone, activity, cranial nerves and any abnormal movements. \\ 5- Cardiac examination: for auscultation of the heart sounds and detection of any congenital heart diseases or signs of heart failure or murmurs.}


6-Abdominal examination: for any abnormality or organomegaly (hepatosplenomegaly).

7- Examination of the external genitalia and back.

III-Prediction of mortality and evaluation of illness severity:

Laboratory Investigations as:

1- Complete blood count

2- $\mathrm{C}$ reactive protein

3 - Serum albumin- serum bilirubin

4- Creatinine

5- Lactate.

Venous blood samples for laboratory tests were collected from all patients in 3 different tubes as follows:

1-Tube containing ethylene diamine tetra-acetic acid (EDTA) and analysed with a Beckman Coulter LH 780 hematology analyser within maximum 1 hour of sample collection.

2- Plain tube for CRP, albumin, bilirubin and creatinine

3- Fluoride tube for lactate estimation

The platelet indices of the patients were analyzed in whole blood. $3 \mathrm{ml}$ of venous blood sample was drawn under complete aseptic conditions (alcohol swab 70\%). CBC parameters including platelet count, mean platelet volume (MPV) and platelet distribution width (PDW) were assessed.

\section{Follow up:}

The follow up of cases was done over 24 hours for 1 week by:
- Arterial blood gases and pH every 12 hours.

- Pulse oximetery continuously during the study. - Clinical data: Heart rate, respiratory rate and chest retractions every 12 hours.

- Length of PICU stay.

- Outcome.

Documentation was done for any clinical deterioration, apnea, worsening hypercapnia, hypoxia and the need for invasive ventilation.

\section{Statistical analysis}

Data collected throughout history, basic clinical examination, laboratory investigations and outcome measures were coded, entered and analyzed using Microsoft Excel software. Data were then imported into Statistical Package for the Social Sciences (SPSS version 20.0) software for analysis. According to the type of data qualitative were represented as number and percentage, quantitative continues group were represented by mean $\pm \mathrm{SD}$, range, median, and interquartile range, the following tests were used to test differences for significance; difference and association of qualitative variable by Chi square test $\left(\mathrm{X}^{2}\right)$. Differences between quantitative independent groups by $\mathrm{t}$ test or Mann-Whitney. $\mathrm{P}$ value was set at $<0.05$ for significant results \& $<0.001$ for high significant result.

\section{RESULTS}

Table (1): CRP and lactate.

\begin{tabular}{|l|c|c|}
\hline & CRP $(\mathrm{mg} / \mathrm{L})$ & Lactate $(\mathrm{mg} / \mathrm{dL})$ \\
\hline Mean & $\mathbf{4 1 . 2 3 5 3}$ & $\mathbf{1 . 6 6 6 3}$ \\
\hline Median & $\mathbf{1 2 . 1 0 0 0}$ & $\mathbf{1 . 5 0 0 0}$ \\
\hline Standard Deviation & $\mathbf{6 9 . 1 9 2 8 8}$ & $\mathbf{0 . 6 0 7 1 4}$ \\
\hline Minimum & $\mathbf{0 . 1 5}$ & $\mathbf{0 . 9 0}$ \\
\hline Maximum & $\mathbf{3 7 9 . 0 0}$ & $\mathbf{3 . 0 0}$ \\
\hline
\end{tabular}

The most frequent cause of admission was respiratory disorders as shown in table 2.

Table (2): Age, sex, PRISM Score, predicted death rate and cause of admission distribution

\begin{tabular}{|c|c|c|c|}
\hline \multirow[t]{2}{*}{ Age / Years } & Mean \pm SD & \multicolumn{2}{|c|}{$2.13 \pm 3.12$} \\
\hline & Median & \multicolumn{2}{|c|}{0.85} \\
\hline \multirow{2}{*}{$\begin{array}{l}\text { PRISM } \\
\text { Score }\end{array}$} & Mean \pm SD & \multicolumn{2}{|c|}{$9.93 \pm 4.5$} \\
\hline & Median & \multicolumn{2}{|c|}{9.0} \\
\hline \multirow{3}{*}{$\begin{array}{l}\text { Predicted } \\
\text { Death Rate }\end{array}$} & Mean \pm SD & \multicolumn{2}{|c|}{$8.2 \% \pm 7.2$} \\
\hline & Median & \multicolumn{2}{|c|}{$5.1 \%$} \\
\hline & & $\mathbf{N}$ & $\%$ \\
\hline \multirow[t]{2}{*}{ Sex } & Female & 46 & 53.5 \\
\hline & Male & 40 & 46.5 \\
\hline \multirow{6}{*}{$\begin{array}{l}\text { Cause of } \\
\text { admission } \\
\text { (system } \\
\text { involved) }\end{array}$} & Respiratory & 28 & $32.6 \%$ \\
\hline & Cardiac & 20 & $23.3 \%$ \\
\hline & Gastrointestinal & 16 & $18.6 \%$ \\
\hline & Neurological & 13 & $15.1 \%$ \\
\hline & Renal & 9 & $10.6 \%$ \\
\hline & Total & 86 & 100.0 \\
\hline
\end{tabular}

Among studied group $(\mathrm{N}=86)$. This table shows that the percentage of mortality was $26.7 \%$ 
Table (3): Outcome distribution among studied group

\begin{tabular}{|c|c|c|c|}
\hline & & $\mathbf{N}$ & $\%$ \\
\hline \multirow{2}{*}{ Outcome } & Died & 23 & 26.7 \\
\hline & Improvement & 63 & 73.3 \\
\hline \multirow{3}{*}{ Mortality } & Survived & 63 & 73.3 \\
\hline & Died & 23 & 26.7 \\
\hline & Total & 86 & 100.0 \\
\hline
\end{tabular}

PRISM score and predicted death rate were significantly higher among died cases (Table 4).

Table (4): Age, Sex, PRISM Score and predicted death rate distribution between died and survived cases.

\begin{tabular}{|c|c|c|c|c|c|c|}
\hline & & & $\begin{array}{c}\text { Died } \\
(\mathrm{N}=23)\end{array}$ & $\begin{array}{c}\text { Survived } \\
(\mathrm{N}=63)\end{array}$ & $\begin{array}{c}\text { Mann } \\
\text { Whitney/ X }\end{array}$ & $P$ \\
\hline \multicolumn{2}{|c|}{ Age (years) } & Mean \pm SD & $2.21 \pm 3.61$ & $2.61 \pm 5.09$ & -0.340 & 0.735 \\
\hline \multicolumn{2}{|c|}{ PRISM Score } & Mean \pm SD & $13.21 \pm 3.88$ & $8.73 \pm 4.12$ & 4.531 & $<0.01$ \\
\hline \multicolumn{2}{|c|}{ Predicted Death Rate } & Mean \pm SD & $13.33 \pm 8.43$ & $6.32 \pm 5.28$ & 3.948 & $<0.01$ \\
\hline \multirow{4}{*}{ Sex } & \multirow{2}{*}{ Female } & \begin{tabular}{|l|}
$\mathbf{N}$ \\
\end{tabular} & 12 & 34 & \multirow{4}{*}{0.022} & \multirow{4}{*}{0.88} \\
\hline & & $\%$ & $52.2 \%$ & $54.0 \%$ & & \\
\hline & \multirow{2}{*}{ Male } & $\mathbf{N}$ & 11 & 29 & & \\
\hline & & $\%$ & $47.8 \%$ & $46.0 \%$ & & \\
\hline \multirow{2}{*}{\multicolumn{2}{|c|}{ Total }} & $\mathbf{N}$ & 23 & 63 & & \\
\hline & & $\%$ & $100.0 \%$ & $100.0 \%$ & & \\
\hline
\end{tabular}

Platelets (PLT) count and albumin were significantly lower among died cases than survived but CRP and lactate were significantly higher among died cases than survived (Table 5).

Table (5): CBC and laboratory parameters distribution between died and survived cases

\begin{tabular}{|c|c|c|c|c|}
\hline & $\begin{array}{c}\text { Died } \\
(\mathrm{N}=\mathbf{2 3})\end{array}$ & $\begin{array}{l}\text { Survived } \\
(\mathrm{N}=63)\end{array}$ & $\begin{array}{c}\text { Mann } \\
\text { Whitney/t }\end{array}$ & $\boldsymbol{P}$ \\
\hline HB (g/dL) & $9.85 \pm 1.74$ & $10.21 \pm 2.02$ & -0.750 & 0.455 \\
\hline RBCS (cells/mcL) & $3.7 \pm 0.95$ & $3.82 \pm 0.89$ & -0.550 & 0.583 \\
\hline PLT (mcL) & $269.43 \pm 72.3$ & $385.19 \pm 62.3$ & -2.600 & 0.011 \\
\hline WBCS (mcL) & $14.16 \pm 3.32$ & $12.49 \pm 2.82$ & 1.089 & 0.279 \\
\hline CRP (mg/L) & $76.37 \pm 17.9$ & $28.4 \pm 4.5$ & 2.974 & 0.004 \\
\hline Total Bilirubin (mg/dl) & $0.64 \pm 0.05$ & $0.63 \pm 0.05$ & 0.071 & 0.943 \\
\hline $\begin{array}{l}\text { Direct Bilirubin } \\
\text { (mg/dL) }\end{array}$ & $0.25 \pm 0.01$ & $0.17 \pm 0.04$ & 1.225 & 0.224 \\
\hline Albumin & $3.38 \pm 0.51$ & $3.78 \pm 0.56$ & -2.279 & 0.025 \\
\hline $\begin{array}{l}\text { Creatinine } \\
(\mu \mathrm{mol} / \mathrm{kg} / \mathrm{day}\end{array}$ & $0.76 \pm 0.02$ & $0.79 \pm 0.03$ & -0.102 & 0.919 \\
\hline Lactate (mg/dL) & $2.39 \pm 0.47$ & $1.4 \pm 0.31$ & 9.669 & $<0.01$ \\
\hline
\end{tabular}




\section{DISCUSSION}

Our study aimed to describe the prognostic value of increased serum lactate in critically ill children and its association with poor outcome.

In the current study the patients were represented as 46 female with percentage of $53.5 \%$ and 40 male with percentage of $46.5 \%$.

Our study showed that there was no significant differences between died and survived as regard age or sex and this was in agreement with Isguder et al. ${ }^{(10)}$ who reported that there was no difference between age and sex distribution of survivor and non survivors children. On the other hand, Ye et al. ${ }^{(11)}$ found that age was significantly different between survivors and nonsurvivors as mortality rate was lower among older children.

Also, our results showed that PRISM score and predicted death rate were significantly higher among died cases and these results were in agreement with Wang et al. ${ }^{(12)}$, Gemke and van Vught ${ }^{(13)}$ and Brady et al. ${ }^{(14)}$ who concluded that PRISM III score is a valid measure of illness severity in the first 24 hours after admission and reflects the clinical picture of a child during the early admission period and is an important tool in predicting mortality and clinical outcomes in the pediatric population.

Complete blood count parameters distributions in our patient showed that platelet count was lower among died cases than survived ones and this was in agreement with many studies covering different age groups. In the neonatal period Elmoneim et al. ${ }^{(15)}$ concluded that platelets count drop within the first 7 days of life independent of thrombocytopenia can be used to predict increased mortality, and the development of later severe morbidities in critically ill preterm neonates. Also Rastogi et al. (16) were in agreement as they reported that decrease in platelet count among preterm neonates is associated with increased mortality.

In the pediatric age group supporting our results Agrawal et al. ${ }^{\left({ }^{(17)}\right.}$, Isguder et al. ${ }^{\left({ }^{(10)}\right.}$ and Ye $\boldsymbol{e t}$ al. (11) studies which concluded separately that high mortality was observed in children with thrombocytopenia.

Also, in adults, there were Zhang et al. ${ }^{(18)}$, Zhang et al. (19), Zampieri et al. ${ }^{(20)}$. These studies demonstrated that critically ill patients with a low platelet count survived for a shorter time than those with normal platelet count.

In addition, $\mathrm{CBC}$ and other laboratory parameters including total bilirubin, direct bilirubin, albumin and creatinine were assessed and found that albumin was lower among died cases than survived and this was observed also by Erdogan $\boldsymbol{e t}$ al. ${ }^{(21)}$ and Leite et al. ${ }^{(3)}$ who concluded that hypoalbuminemia at PICU admission was found to predict mortality in critically ill children, and shown to be associated with a higher mortality rate.

Regarding serum lactate it was found to be higher among died cases than survived ones and this result was in agreement with many studies which demonstrated that either admission lactate or peak lactate concentration were associated with mortality in adults (Kruse et al. ${ }^{(22)}$, Gustavsson et al. ${ }^{(23)}$ and Martin et al. ${ }^{(24)}$ and also goes hand in hand with a number of studies which verified the use of hyperlactatemia as a prognostic index in critically ill children who are admitted to the PICU (Koliski $\boldsymbol{e t}$ al. ${ }^{(25)}$, Morris et al. ${ }^{(26)}$ and Isguder et al. $\left.{ }^{(10)}\right)$.

Also, we noticed that CRP was significantly higher among died cases than survived ones and this was similarly reported by Isguder $\boldsymbol{e t}$ al. ${ }^{(10)}$ and Ye $\boldsymbol{e t}$ al. (11) who demonstrated that CRP, was higher in the nonsurvivors group and was associated with mortality.

\section{CONCLUSION}

Hyperlactatemia in critically ill children is associated with worse outcome in critically ill patient in PICU.

\section{RECOMMENDATIONS}

Multicentre studies recruiting more infants with larger samples are recommended for better assessment of the prognostic value of hyperlactatemia.

\section{REFERENCES}

1. Meregalli A, Oliveira R, Friedman, G (2004): Occult hypoperfusion is associated with increased mortality in hemodynamically stable, high-risk, surgical patients. Critical Care, 8(2): 60-65.

2. Dellinger R, Levy M, Rhodes A et al. (2013): Surviving Sepsis Campaign: international guidelines for management of severe sepsis and septic shock, 2012. Intensive Care Medicine, 39(2): 165-228.

3. Leite $\mathrm{H}$, Rodrigues $\mathrm{A}$, de Oliveira $\mathrm{S}$ et al. (2016): Serum albumin is an independent predictor of clinical outcomes in critically ill children. Pediatric Critical Care Medicine, 17(2): 50-57.

4. Vincent J, Quintairos E, Couto L et al. (2016): The value of blood lactate kinetics in critically ill patients: a systematic review. Critical Care, 20(1): 257-63.

5. Poddar B, Gurjar M, Singh S et al. (2016): Reduction in procalcitonin level and outcome in critically ill children with severe sepsis/septic shock-A pilot study. Journal of Critical Care, 36: 230-233.

6. Li Y, Bai Z, Li M et al. (2015): U-shaped relationship between early blood glucose and mortality in critically ill children. BMC Pediatrics, 15: 88-93.

7. Raman S, Prince N, Hoskote A et al. (2016): Admission $\mathrm{PaO} 2$ and mortality in critically ill children: A Cohort Study and Systematic Review. Pediatric Critical Care Medicine, 17(10): 444-450.

8. Bechard L, Duggan C, Touger-Decker R et al. (2016): Nutritional status based on body mass index is associated with morbidity and mortality in mechanically 
ventilated critically ill children in the PICU. Critical Care Medicine, 44(8): 1530-1537.

9. Okorie O, Dellinger P (2011): Lactate: biomarker and potentialtherapeutic target. Crit Care Clin., 27(2):299326.

10. Isguder R, Ceylan G, Agin H et al. (2016): Increased mean platelet volume in children with sepsis as a predictor of mortality. The Turkish Journal of Pediatrics, 58(5): 503-511.

11. Ye S, Zhang Y, Zhang C et al. (2018): Are platelet volume indices related to mortality in hospitalized children on mechanical ventilation? Journal of International Medical Research, 46(3): 1197-1208.

12. Wang J, Wu J, Chen Y (2001): Validity of the updated pediatric risk of mortality score (PRISM III) in predicting the probability of mortality in a pediatric intensive care unit. Acta Paediatrica Taiwanica, 42(6): 333-337.

13. Gemke R, van Vught J. (2002): Scoring systems in pediatric intensive care: PRISM III versus PIM. Intensive Care Medicine, 28(2): 204-207.

14. Brady A, Harrison D, Black $S$ et al. (2006): Assessment and optimization of mortality prediction tools for admissions to pediatric intensive care in the United Kingdom. Pediatrics, 117(4): 733-742.

15. Elmoneim A, Zolaly M, El-Moneim E et al. (2015): Prognostic significance of early platelet count decline in preterm newborns. Indian Journal of Critical Care Medicine, 19(8): 456-461.

16. Rastogi S, Olmez I, Bhutada A et al. (2011): Drop in platelet counts in extremely preterm neonates and its association with clinical outcomes. Journal of Pediatric Hematology/Oncology, 33(8): 580-584.

17. Agrawal S, Sachdev A, Gupta D et al. (2008): Platelet counts and outcome in the pediatric intensive care unit. Indian Journal of Critical Care Medicine, 12(3): 102108.
18. Zhang Z, Xu X, Ni H et al. (2014): Platelet indices are novel predictors of hospital mortality in intensive care unit patients. Journal of Critical Care, 29(5): 881-886.

19. Zhang S, Cui Y, Diao M et al. (2015): Use of platelet indices for determining illness severity and predicting prognosis in critically ill patients. Chinese Medical Journal, (Engl), 128(15): 2012-2018.

20. Zampieri F, Ranzani O, Sabatoski V et al. (2014): An increase in mean platelet volume after admission is associated with higher mortality in critically ill patients. Annals of Intensive Care, 4, 20.

21. Erdogan S, Oto A, Bosnak M (2015): The relation between mean platelet volume and mortality in critical pediatric patients. The Turkish Journal of Pediatrics, 57(6): 605-610.

22. Kruse O, Grunnet N, Barfod C (2011): Blood lactate as a predictor for in-hospital mortality in patients admitted acutely to hospital: a systematic review. Scandinavian Journal of Trauma, Resuscitation and Emergency Medicine, 19: 74-79.

23. Gustavsson L, Andersson L, Brink M et al. (2012): Venous lactate levels can be used to identify patients with poor outcome following community-onset norovirus enteritis. Scandinavian Journal of Infectious Diseases, 44(10): 782-787.

24. Martin J, Blobner M, Busch R et al. (2013): Point-ofcare testing on admission to the intensive care unit: lactate and glucose independently predict mortality. Clinical Chemistry and Laboratory Medicine, 51(2): 405-412.

25. Koliski A, Cat I, Giraldi D, Cat M (2005): [Blood lactate concentration as prognostic marker in critically ill children]. Journal de Pediatria, 81(4): 287-292.

26. Morris K, McShane P, Stickley J et al. (2012): The relationship between blood lactate concentration, the Paediatric Index of Mortality 2 (PIM2) and mortality in paediatric intensive care. Intensive Care Medicine, 38(12): 2042-2046. 